\title{
Improvement of Thermal Stability of Electrospun PAN Fibers by Various Additives
}

\author{
Young-Seak Lee ${ }^{1}$, Min II Kim ${ }^{1}$, Ji Sun Im $^{1}$ and Se-Jin In $^{2, \wedge}$ \\ ${ }^{1}$ Department of Fine Chemical Engineering and Chemistry, Chungnam National University, Daejeon 305-764, Korea \\ ${ }^{2}$ Department of Fire and Disaster Protection Engineering, Woosong University, Daejeon 300-718, Korea \\ ‘e-mail: sjin@wsu.ac.kr \\ (Received August 12, 2008; Accepted September 16, 2008)
}

\begin{abstract}
In order to improve the thermal stability of PAN-based electrospun fibers, AP-PER-MEL and $\mathrm{TiO}_{2}$ were added in to the fibers as additives. The polymer composite with uniformly mixed additional agents was obtained. In case of non-treated sample, the fibers were burn off completely with high rate within $620^{\circ} \mathrm{C}$. But in case of treated samples (EF-M and EF-MT), it is sure that the thermal stability was improved by studying TGA data and ISO flammability test about 20 and $30 \%$, respectively. A synergy effect of adding two kinds of agents (AP-PER-MEL and $\mathrm{TiO}_{2}$ ) into PAN-based electrospun fibers was confirmed. Through SEM images, it is confirmed that the fiber shape can be kept even after addition of agents (AP-PER-MEL and $\mathrm{TiO}_{2}$ ). Finally the thermal stability of fibers was largely developed with keeping the nature of PAN-based fibers effectively.
\end{abstract}

Keywords : Thermal stability, Fiber, Electrospinning

\section{Introduction}

The protection of materials against fire has become an important issue in the construction industry. In general, flame retardant can be classified into two groups: non-intumescent and intumescent agents [1]. The addition of intumescent flame-retardant is one of the easiest and efficient ways to protect materials against fire [2,3]. It presents two main advantages: it can prevent heat from penetrating and flames from spreading $[4,5]$. The action of the flame retardant can occur across both or either of the vapor phase and the condensed phase. The combustion is a complex process: there may be different mechanisms with different matrix fibers and different flame retardants. The mechanism of this fire retardant is assumed that the char acts as a physical barrier against heat transmission and oxygen diffusion, thus preventing pyrolysis of the material to volatile combustible products $[6,7]$.

In this study, as a material, which must have better thermal stability, electrospun fibers were selected, because even though they have various kinds of advantages from nanoscale, the thermal stability is poor. Especially, we tried to get the composite, which is consisted polymer source with additional agents (AP-PER-MEL and $\mathrm{TiO}_{2}$ ) with well mixed uniformly, because traditional methods such as coating and surface treatment have the effect until the additional agent can be resized on the surface.

\section{Experimental}

\subsection{Electrospinning and heat treatment}

It is important to decide a proper solvent to dissolve polymer completely for the electrospinning polymer solution. In this side, boiling point of solvent should be regarded. It is well known that solvent is volatilized with formation of polymer jet. If the boiling point of solvent is too low, solvent would be volatilized before forming polymer jet. In case of using solvent having high boiling point, the formation of electrospun fiber form would be difficult due to too low density of polymer solution during electrospinning. So far $\mathrm{N}, \mathrm{N}$-dimethyl formamide (DMF) is considered as the best solvent among various organic solvents due to proper boiling point $\left(153^{\circ} \mathrm{C}\right)$ and excellent conductivity (conductivity = $10.90 \mu \mathrm{S} / \mathrm{cm}$, dipole moment $=3.82$ debye) [8]. Polyacrylonitrile (PAN, d=1.184, 181315, Aldrich) was used as a polymer source. Melamine (MEL, $\mathrm{C}_{3} \mathrm{H}_{6} \mathrm{~N}_{6}$, JUNSEI, 4L1528), ammonium phosphate (AP, $\mathrm{NH}_{4} \mathrm{H}_{2} \mathrm{PO}_{4}$, SAMCHUN CHEMICALS, 021306) and pentaerythritol (PER, $\mathrm{C}_{5} \mathrm{H}_{12} \mathrm{O}_{4}$, ALDRICH, 236241-50G) were used as the intumescent.

Four polymer solutions were prepared with various weight ratios. The preparing conditions of samples are listed in Table 1 in detail with final product names. The prepared polymer solution was ejected from the syringe tip to the aluminum foil covered collector by using an electrospinning apparatus. The prepared polymer solution was then injected into a $30 \mathrm{ml}$ syringe having a capillary tip (18G, inner diameter: $1.27 \mathrm{~mm}$ ) and then the syringe was placed in a KD scientific syringe pump (Model 100). Electric power was applied with a high voltage power supply (NT-PS-25K, NTSEE Co., Korea) using $15 \mathrm{kV}$. The details have been presented elsewhere [9]. These electrospun fibers were thermally treated at $250^{\circ} \mathrm{C}$ for $8 \mathrm{~h}$ in order to make fiber 
Table 1. The Preparation Method of Samples

\begin{tabular}{cccc}
\hline Sample name & EF & EF-M & EF-MT \\
\hline PAN $(\mathrm{g})$ & 3 & 3 & 3 \\
DMF $(\mathrm{g})$ & 27 & 27 & 27 \\
Melamine $(\mathrm{g})$ & - & 0.63 & 0.63 \\
Pentaerythritol $(\mathrm{g})$ & - & 0.66 & 0.66 \\
Ammonium Phosphate $(\mathrm{g})$ & - & 1.14 & 1.14 \\
$\mathrm{TiO}_{2}(\mathrm{~g})$ & - & - & 0.39 \\
\hline
\end{tabular}

stable at high temperature through oxidation step. This procedure was conducted under air atmosphere and $1^{\circ} \mathrm{C} / \mathrm{min}$.

\subsection{Characterization of samples}

Following electrospinning, representative samples were taken from each mat for characterization of morphology and pore structure. The samples were dried at $110^{\circ} \mathrm{C}$ and required only sputter coating with gold and the coated samples were then analyzed at an accelerating voltage of 10 $\mathrm{kV}$ for scanning electron microscopy (SEM) (VegaII Lmu Tescan Co.) evaluation with 10000 magnification. The average diameters of all samples were estimated by soft program (VegalI Lmu Tescan Co.).

In order to investigate the thermal stability of samples, two tests were carried out by using thermal gravimetric analysis (TGA, 2960SDT, TA Instruments) and ISO flammability tester. TGA data was obtained by controlling the temperature from room temperature to $1000^{\circ} \mathrm{C}$. The points were recorded at every $5^{\circ} \mathrm{C}$ elevation. In case of flammability tester, the small fiber is moving near the surface of samples with interval of 4 seconds as shown in Fig. 1. The radiation heat was given by using $3 \mathrm{~W} / \mathrm{cm}^{2}$.

\section{Results and Discussion}

\subsection{Morphology of samples}

In order to investigate the morphology of sample surface, the SEM images are presented in Fig. 2. All of samples are kept their original fiber shape even after adding intumescent

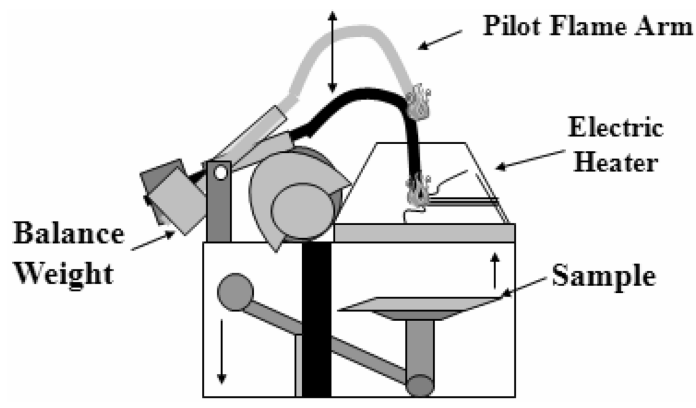

Fig. 1. ISO flammability tester.
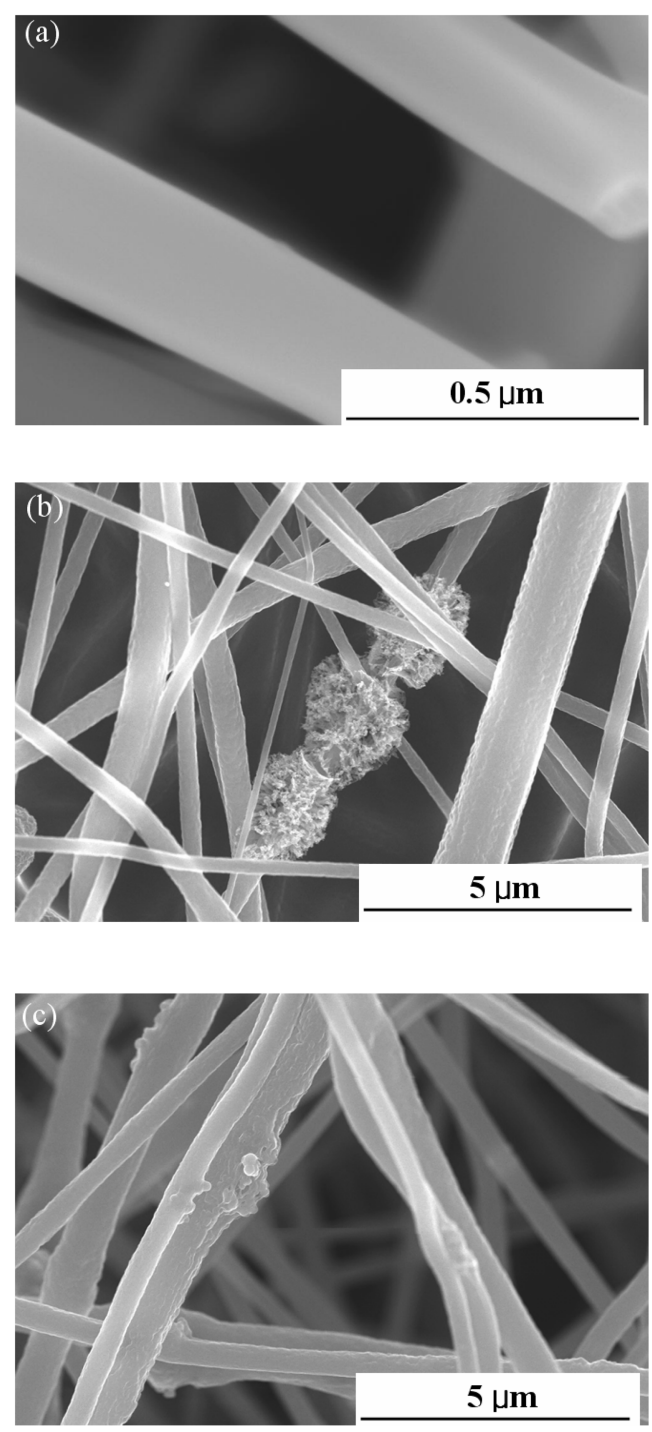

Fig. 2. SEM image of sample; (a): EF, (b): EF-M and (c): EF-MT.

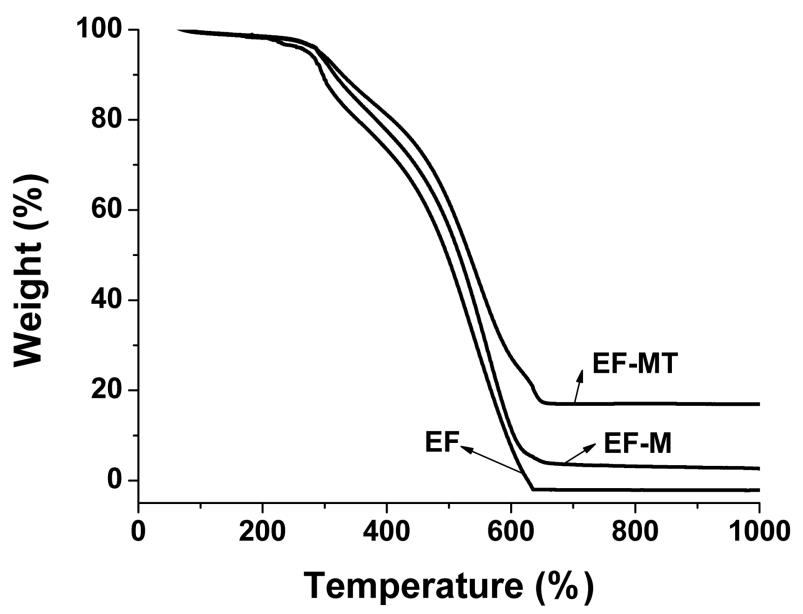

Fig. 3. TGA data of samples. 


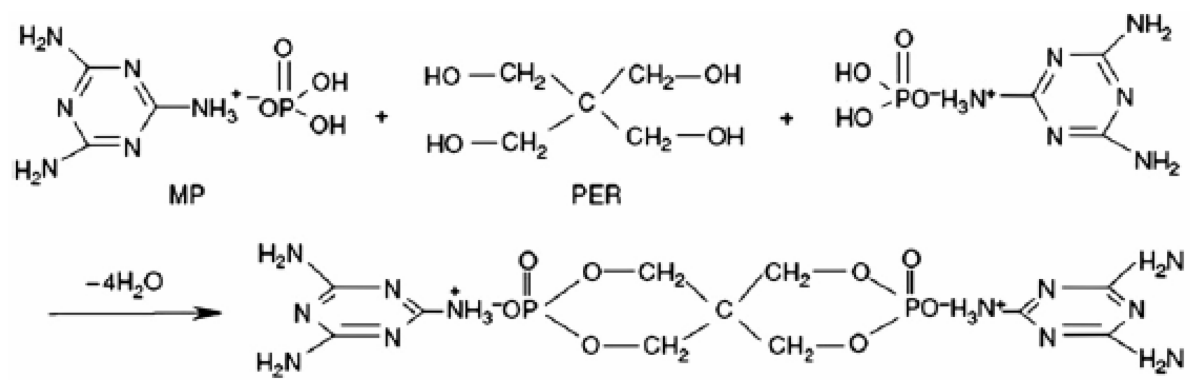

Fig. 4. Reaction of melamine phosphate with pentaerythritol.

agents. In case of EF, the clear and smooth surface of fibers is observed with regular diameter of fibers about $250 \mathrm{~nm}$. After addition of intumescent agents, some of fibers are covered with intumescent agents that can work for the retardant. In case of EF-MT, the clusters of additional agents are entangled along the fibers.

\subsection{Thermal stability of samples}

The thermal stability of samples was investigated by TGA data in Fig. 3. In case of EF, the weight is decreased in the range from 280 to $620^{\circ} \mathrm{C}$ completely. But the EF-M shows the different tendency which the curve decreased more slightly than it of EF, because the material was obtained from the reaction among AP-PER-MEL agents as shown in Fig. 4 [10]. It seems that the AP-PER-MEL hinders the burn off of fibers and eventually remains even up to $1000^{\circ} \mathrm{C}$. In case of adding AP-PER-MEL and $\mathrm{TiO}_{2}$, the effect of additional agents is observed significantly. The curve of weight is decreased most slightly among three samples indicating the evidence of hindering the burn off of fibers.

\subsection{ISO flammability test}

The flammability test was carried out and the results were shown in Fig. 5. The time of first gas and flammability shows similar trend with increased time about $25 \%$. The

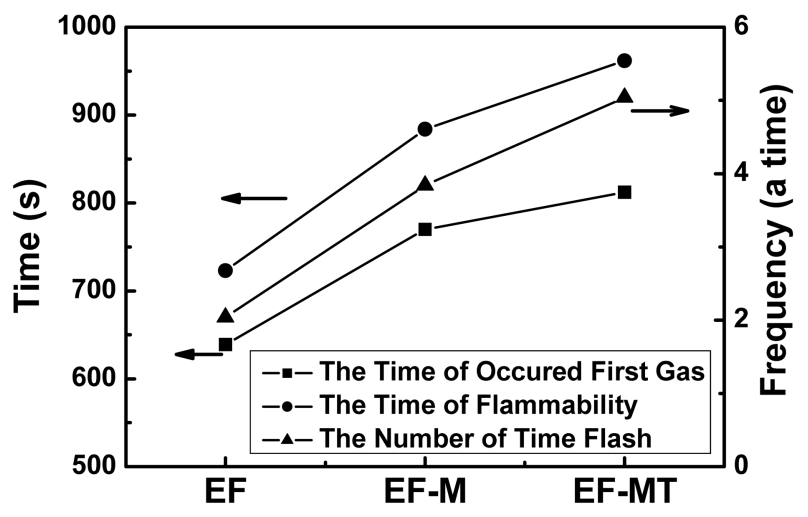

Fig. 5. ISO flammability data of samples. number of time flash also increased twice from 2 to 4 . These results indicate that the first reaction by heat can be delayed by additional agents effectively. Also in case of using APPER-MEL with $\mathrm{TiO}_{2}$, the synergy effect might occur as explained above.

\section{Conclusion}

In order to improve the thermal stability of PAN-based electrospun fibers, AP-PER-MEL and $\mathrm{TiO}_{2}$ were used as the additional agents. In case of EF, the fibers were burn off completely with high rate within $620^{\circ} \mathrm{C}$. But in case of EF$\mathrm{M}$, it was confirmed that the thermal stability was improved through TGA data and ISO flammability test about $20 \%$. The synergy effect of adding two kinds of agents (AP-PERMEL and $\mathrm{TiO}_{2}$ ) was investigated. Through SEM images, it is confirmed that the fiber shape can be kept even after addition of agents (AP-PER-MEL and $\mathrm{TiO}_{2}$ ). Finally the thermal stability of fibers was improved with keeping the nature of PAN-based fibers effectively.

\section{References}

[1] Li, G.; Liang, G.; He, T.; Yang, Q.; Song, X. Polym. Degrad. Stabil. 2007, 92, 569.

[2] Vandersall, H. L. J. Fire Flamm. 1971, 2, 97.

[3] Rhys, J. A. Fire Mater. 1980, 4, 154.

[4] Zhang, G. C.; Gu, J. W. J. Mater. Eng. 2006, 1, 47.

[5] Duquesnea, S.; Magnetb, S.; Jamaa, C.; Delobelc, R. Surf. Coat. Tech. 2004, 302, 180.

[6] Camino, G.; Costa, L.; Trossarelli, L. Polym. Degrad. Stabil. 1984, 7, 221.

[7] Bertelli, G.; Costa, L.; Fenza, S.; Marchetti, E.; Camino, G.; Locatelli, R. Polym. Degrad. Stabil. 1988, 20, 295.

[8] Xiao, X. C.; Jiang, W. H.; Song, L. X.; Tian J. F.; Hu, X. F. Diam. Relat. Mater. 2000, 9, 1782.

[9] Im, J. S.; Kwon, O.; Kim, Y. H.; Park, S. J.; Lee, Y. S. Micropor. Mesopor. Mat. 2008, 115, 514.

[10] Wang, D. Y.; Liu, Y.; Wang, Y. Z.; Artiles, C. P.; Hull, T. R.; Price, D. Polym. Degrad. Stabil. 2007, 92, 1592. 